\title{
THE METHOD OF INCREASING THE THERMOSTABILITY OF FILLED POLYMERS
}

\author{
Nikolay Romanovich Prokopchuk \\ Doctor of Chemical Sciences, Professor, \\ Correspondent Member of NAS of Belarus, \\ Head of Department of Petrochemical Synthesis Technology and Polymeric Materials Processing, \\ Belarusian State Technological University \\ prok_nr@mail.ru \\ Sverdlova St., 13-a, 220006 Minsk, Republic of Belarus
}

\section{Liliya Alekseevna Lenartovich}

Candidate of Technical Sciences, Junior Researcher,

Department of Petrochemical Synthesis Technology and Polymeric Materials Processing,

Belarusian State Technological University

liliya.popova@mail.ru

Sverdlova St., 13-a, 220006 Minsk, Republic of Belarus

\begin{abstract}
The individual contribution of stabilizers and fillers into the increase of thermal stability of a polymer-matrix of composite materials at their joint presence in the composite is estimated in this paper. The increase of thermal stability of polypropylene composites in the process of pre-saturation of the surface of fillers by thermal stabilizers compared to their individual introduction into the polymer is determined. A method of saturation of the surface of fillers by stabilizers is proposed. The mechanism of a prolonged and direct action of stabilizers desorbing from the surface of the filler is explained. It leads to the increase of the thermal stability of stabilized filled polypropylene compositions obtained by the proposed method by $10-40 \%$ in comparison with the traditional one. It simultaneously reduces the amount of used stabilizers in 1.25 times.
\end{abstract}

Key words: a stabilizer, a filler, a polymer composite material, adsorption, polypropylene composites.

\section{Introduction}

Now under existing conditions of the increase of market competition the task of producers of polymeric materials is the constant improvement of the quality of created products. The important indicators of comparison are not only physical and mechanical characteristics of the used materials, but also their durability. The created polymer composite materials (PCM) are heterogeneous systems consisting of several components. While creating PCM we use fillers that give to the materials a valuable set of properties, and stabilizers that reduce the negative impact of factors of the environment on the material and its protection during the recycling process. The impact of these components on each property of PCM is sufficiently studied $[3 ; 6 ; 8$; 
11]. However, the comprehensive research aimed at studying the individual contribution of stabilizers and fillers in their combined influence on the properties of PCM are not numerous [9; 12-14]. Such studies are highly relevant, as the use of their results is necessary to create a scientific well grounded approach while selecting components and technology for PCM creation.

While creating PCM, the choice of dosage of stabilizing additives for polymers, containing the fillers is often determined by optimal concentration of stabilizers accepted for the unfilled polymer. Thus, the effect of the filler on the change of properties of PCM because of aging is not taken into consideration. It can lead to the inefficiency of the action of the stabilizer, and to its possible over-expenditure. This may be due to the fact that the necessary concentration of the stabilizer at various filler content may vary compared to the unfilled polymer either in the direction of increasing or decreasing, that depends on the ability of the filler to have a stabilizing or opposite effect on the matrix, and on its ability to adsorb a stabilizer. The study of the combined action of stabilizers and fillers, the creation of new methods of their introduction will allow to increase the resistance of the compositions to various kinds of aging, to exclude cases of overdose of stabilizers, and hence to reduce the cost of the final product.

\section{Experimental Procedure}

The composite materials based on PP (Caplene 01030) and containing fillers and stabilizers were the object of the study. Fine marble of Omyacarb 2-UR brand (OMYA RUS, Russia), talc of Fintalk M30 brand (Mondo Minerals, Finland), fiberglass (FG) of "Polotsk Fiberglass" production (Belarus) were used as fillers. Industrially used additives of well-known manufacturers: Irganox 1010, Irganox B561 (BASF, Germany) and Sandostab P-EPQ (Clariant, Switzerland) were applied as stabilizers. The samples were prepared by molding under pressure in the injection moulding machine BOY 22A (Dr. Boy, Germany). Thermal aging of the samples was carried out in an oven at $150^{\circ} \mathrm{C}$. The concentration of a stabilizer in the composition was up to $1 \%$ by weight, filler content $-20 \%$ by weight.
In accordance with GOST 11262-80 elongation at break $\left(\varepsilon_{b}, \%\right)$ before and after the thermal aging (T2020 DC10 SH tensometer, Alpha Technologies, USA) was determined. Ambient air temperature $-20^{\circ} \mathrm{C}$, speed of top grip motion $50 \mathrm{~mm} / \mathrm{min}$, number of samples -10 . The calculation of the activation energy of thermal oxidative destruction $E_{a}$ was carried out by Broido computational method using the TGA curves, filmed on the device TGA/DSCI (Mettler Toledo, Switzerland). We used the method of IRS to prove the adsorption of stabilizers on the filler's surface (Nexus ESP, Thermo Nicolet, USA). The infrared spectra were carried out with program Omnic v6.0. Nitrogen adsorption isotherms were obtained by BET method (Brunour, Emmet, Teller) on instrument NOVA 2200. Gaseous nitrogen with operation temperature of $77 \mathrm{~K}$ was obtained by evaporation of liquid nitrogen.

\section{Research Results and Discussion}

To study the influence of mode of introduction of stabilizing additives into the polymer matrix of PCM on the properties of composites they were prepared by traditional process and also with preliminary saturation of filler surface by stabilizers from solutions.

The study of the stabilizer adsorption from the polymer melt causes definite difficulties, so the adsorption of stabilizing additives from their solutions was studied. The solvent must meet certain requirements: 1) to dissolve a sufficient amount of investigated stabilizer for the performance of the experiment; 2) to be optically transparent; 3) not to be stained when tested substances are dissolved. It was experimentally found that Irganox 1010 and Irganox B561 are highly soluble in acetone. Sandostab P-EPQ is not soluble in acetone but soluble in n-propanol to form a transparent solution. Stabilizer solutions must be optically transparent for the possibility of determining the concentration according to a refractive index (refractometric method). Investigated fillers marble, talc and chopped fiberglass were used as the adsorbents.

We studied the adsorption interaction at the division border of the phases filler stabilizer solution. For this purpose adsorption isotherms of stabilizing additives on the fillers were obtained by standard methods [4]. Used fillers were 
previously washed in organic solvents. The washing of fillers was performed in order to remove possible impurities on their surface and not to skew the results of the experiment. Fillers were placed in a pure solvent and with vigorous stirring were washed three times. The amount of adsorbed material per unit of filler weight at different concentrations of the equilibrium solution was calculated after a preliminary study of the kinetics of adsorption equilibrium at $20^{\circ} \mathrm{C}$. According to the results of the experiment the values of limiting adsorption of each stabilizer on various fillers were determined, as well as adsorption isotherms were built.

Adsorption isotherms of stabilizers on fillers are shown in Fig. 1. The obtained data indicate

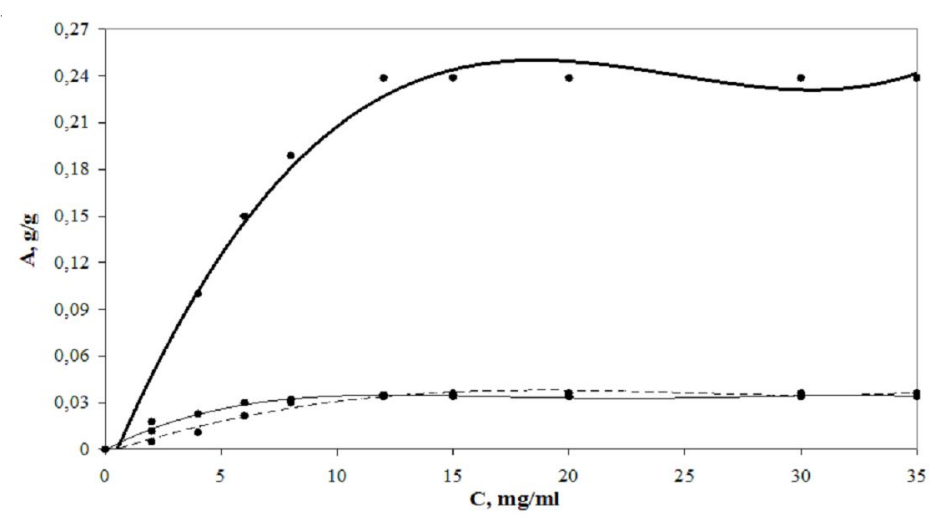

a

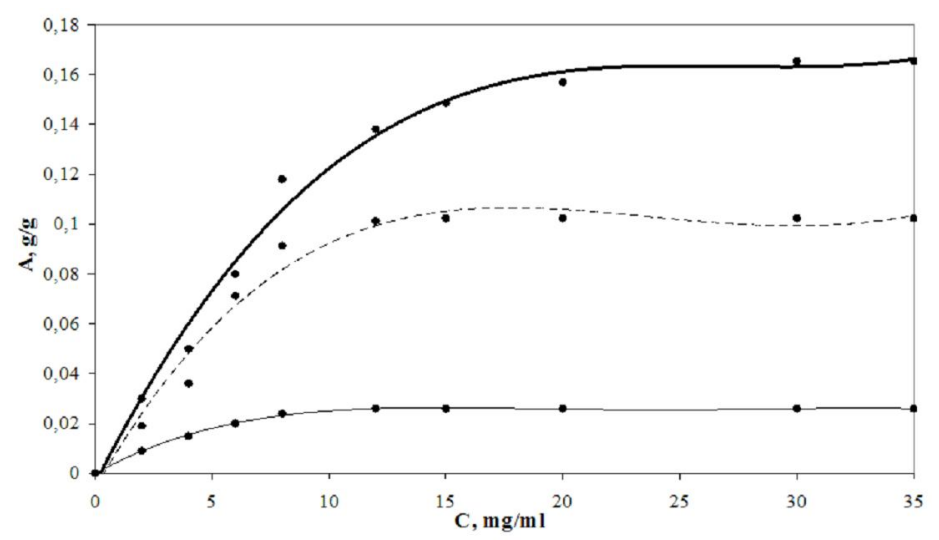

b

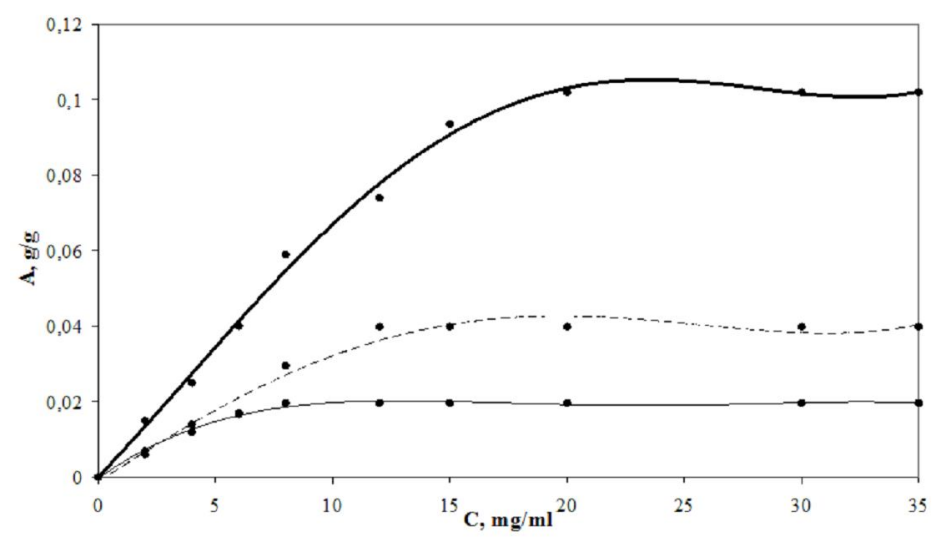

c

Irganox $1010 \quad-\quad$ Sandostab P-EPQ

Irganox B561

Fig. 1. Adsorption isotherms of different stabilizing additives on fillers:

$a$ - fiberglass; $b$ - marble; $c$ - talc 
that the highest value of the maximum absorption is characteristic of the stabilizer Irganox 1010 and varies from 102 to $239 \mathrm{mg} / \mathrm{g}$ depending on the filler used.

Irganox 1010 is related to the phenolic type of stabilizers, in the structure of which the polar carbonyl and hydroxyl groups capable of forming hydrogen bonding with the adsorption centers on the filler surface are present. The adsorption of the stabilizer is also possible due to the formation of donor-acceptor complexes, as well as $\pi$ electron - protone complexes $[2 ; 10]$.

The Sandostab P-EPQ contains only the benzene rings. In this case the adsorbtion process is possible only with the use of one mechanism due to the interaction of $p$-electrons of the benzene rings with the surface of fillers. For Irganox B561, consisting of phenolic and phosphorus-containing stabilizers, there is the least adsorption on all fillers due to the possibility of competitive adsorption of two components [7].

Therefore, it appears that the interaction of the stabilizer Irganox 1010 with the surface of fillers containing active groups is the strongest. The highest values of the limit adsorption for all stabilizers are observed on fiberglass and marble, the smallest - on talc.

The treatment of the surface of fillers with the solutions of stabilizes through the course of adsorption processes allows to fix stabilizing additives purposefully. The stabilizer retains the ability to desorb from the surface of the filler, it does not lose its function. The presence of adsorbed stabilizes on the filler surface is confirmed by IRS. The spectrum of marble after the treatment and subsequent washing of a stabilizer comprises characteristic absorption strips of Irganox 1010: $3640 \mathrm{~cm}^{-1}, 766 \mathrm{~cm}^{-1}$, $1742 \mathrm{~cm}^{-1}$. The displacement of the absorption strip in the region of $3000-3600 \mathrm{~cm}^{-1}$ indicates the interaction of the surface hydroxyl groups of the filler. The data indicate a strong adsorption interaction of a stabilizing additive and marble. Similar spectra are recorded for all investigated fillers and stabilizers. It has been established that the smallest amount of adsorbed stabilizers is present on the surface of talc.

For the study of adsorption processes on the surface of fillers to modify the surface structure the BET method was used [5].

Fig. 2 shows the nitrogen sorption curves obtained for marble, before and after its processing by the solution of stabilizer Irganox 1010. Similar curves were obtained for talc and fiberglass.

From the Fig. 2 it is clear that after the surface treatment by the solution the concentration of the active surface centers is reduced because the pre-adsorption of the stabilizer reducing the adsorption of nitrogen on the filler after the treatment occurs (curve 2). These curves can serve as an indirect confirmation of the adsorption of the stabilizer on the surface of the filler and correlate with the data of adsorption isotherms from solutions of stabilizers.

To study the effect of a new method of the introduction of previously saturated fillers by stabilizers on the properties of the compositions the change of deformation and strength characteristics of the composition before and after

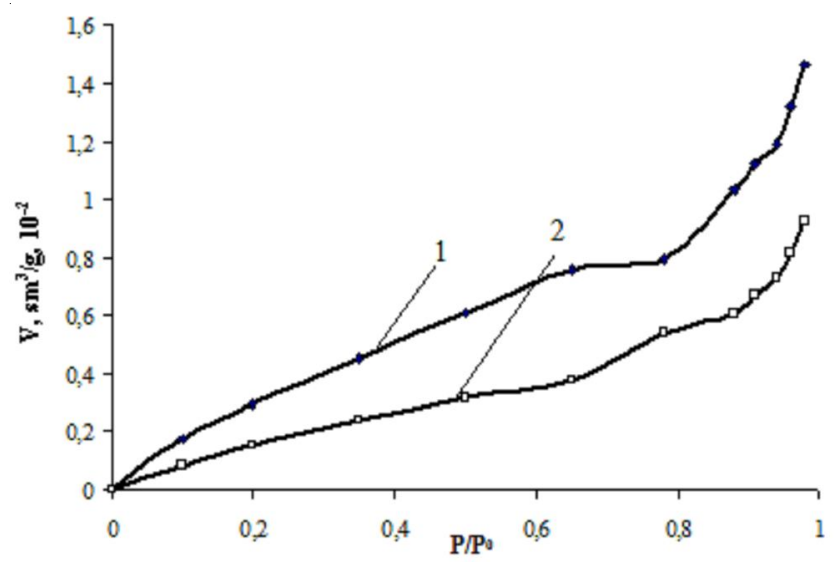

Fig. 2. The adsorption isotherms of nitrogen on marble:

1 - adsorption isotherm of the original marble; 2 - adsorption isotherm of marble after saturation of its stabilizer 


\section{ТЕХНИКО-ТЕХНОЛОГИЧЕСКИЕ ИННОВАЦИИ}

aging was evaluated. The most sensitive indicator of the fall of properties with aging is the change of values of relative elongation at break [1], so the effectiveness of the action of stabilizing additives was evaluated according to this indicator. Fig. 3 shows the values of relative elongation at break after $250 \mathrm{~h}$ of aging of the compositions obtained by the traditional way, and after preadsorption of stabilizers on the surface of the fillers. For compositions obtained by the traditional way $\varepsilon_{p}$ for samples with only optimal concentration of stabilizers was shown.

For compositions containing marble and FG the weakening effect of the action of Sandostab stabilizer and filler on the matrix is observed (samples $11,18)$, as $\varepsilon_{b}$ values are lower than those of unstabilized filled PP (samples 8,15 ), indicating that the action of the stabilizer is inefficient in filled PP. The use of Irganox 1010 and Irganox B561 at a conventional method of introduction leads to increased resistance to temperature (samples 2, 6, $9,13,16,20)$, so there is the enhancing effect of the stabilizer and filler. For the compositions produced by the novel process, there is a significant increase in resistance to the thermal oxidation destruction (samples 3, 10, 12, 14, 21). For the composition comprising Irganox B561 such effect is not observed (sample 7). This is due to the negligible adsorption of an additive on the surface of talc, that correlates with the adsorption data (Fig. 1, c). Perhaps this amount of a stabilizer is not sufficient for long-term protection of the polymer during the aging time of $250 \mathrm{~h}$. The use of marble with pre-adsorbed stabilizer Irganox 1010 (sample 10) results in a significant (40\%) increased thermostability, suggesting the promise of this method.

In order to confirm the results of the increase of the thermal stability of the compositions obtained by a new method, an independent method of the energy activation definition of thermooxidative destruction was used. The results obtained are shown in the form of examples of non-aged stabilized and non-stabilized PP compositions containing a marble filler (Fig. 4). When marble and stabilizers Irganox 1010 and Irganox B561 are jointly introduced, the effect of the increase of resistance to thermal aging is observed (samples 4 and 10). In the case of the use of stabilizer Sandostab P-EPQ there is no increase in the activation energy values (sample 7), the stabilizing effect is not observed, that correlates with the relative elongation at break data (Fig. 3, sample 11). Thus, the effect of increasing resistance to thermal aging and the

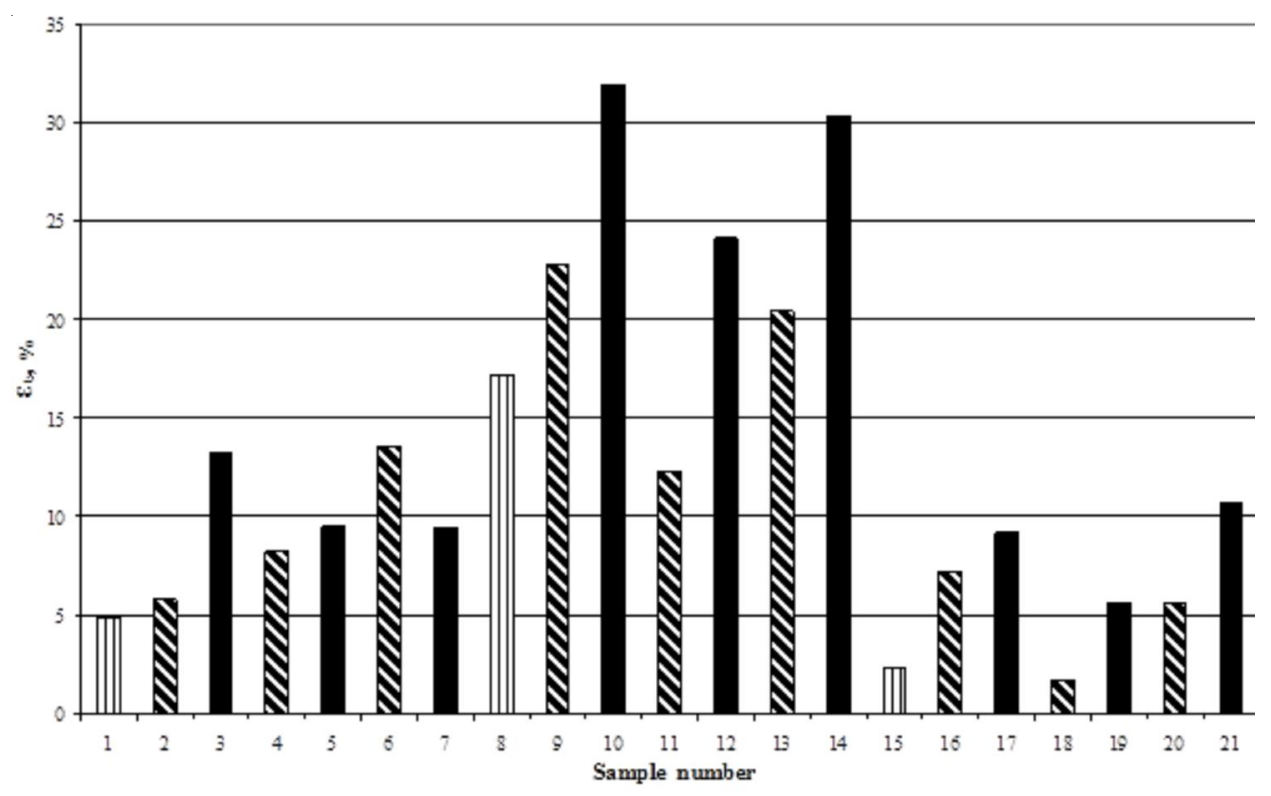

Fig. 3. The values of relative elongation of the compositions after accelerated aging for $250 \mathrm{~h}$ :

$1-\mathrm{PP}+\mathrm{t} ; 2-\mathrm{PP}+\mathrm{t}+\mathrm{I} 1010(1 \%) ; 3-\mathrm{PP}+\mathrm{t}+\mathrm{I} 1010(\mathrm{a}) ; 4-\mathrm{PP}+\mathrm{t}+\mathrm{s}(0.7 \%) ; 5-\mathrm{PP}+\mathrm{t}+\mathrm{s}(\mathrm{a}) ;$ $6-\mathrm{PP}+\mathrm{t}+\mathrm{Ib} 561(0.7 \%) ; 7-\mathrm{PP}+\mathrm{t}+\mathrm{Ib} 561(\mathrm{a}) ; 8-\mathrm{PP}+\mathrm{mr} ; 9-\mathrm{PP}+\mathrm{mr}+\mathrm{I} 1010(0.5 \%) ; 10-\mathrm{PP}+\mathrm{mr}+\mathrm{I} 1010$ (a); $11-\mathrm{PP}+\mathrm{mr}+\mathrm{s}(0.5 \%) ; 12-\mathrm{PP}+\mathrm{mr}+\mathrm{s}(\mathrm{a}) ; 13-\mathrm{PP}+\mathrm{mr}+\mathrm{Ib} 561(0.7 \%) ; 14-\mathrm{PP}+\mathrm{mr}+\mathrm{Ib} 561(\mathrm{a}) ; 15-\mathrm{PP}+\mathrm{FG} ;$

$16-\mathrm{PP}+\mathrm{FG}+\mathrm{I} 1010(0.5 \%) ; 17-\mathrm{PP}+\mathrm{FG}+\mathrm{I} 1010(\mathrm{a}) ; 18-\mathrm{PP}+\mathrm{FG}+\mathrm{s}(0.7 \%) ; 19-\mathrm{PP}+\mathrm{FG}+\mathrm{s}(\mathrm{a}) ;$ $20-\mathrm{PP}+\mathrm{FG}+\mathrm{Ib} 561(0.7 \%) ; 21-\mathrm{PP}+\mathrm{FG}+\mathrm{Ib} 561(\mathrm{a}) ;(\mathrm{a})-$ preliminary adsorption 


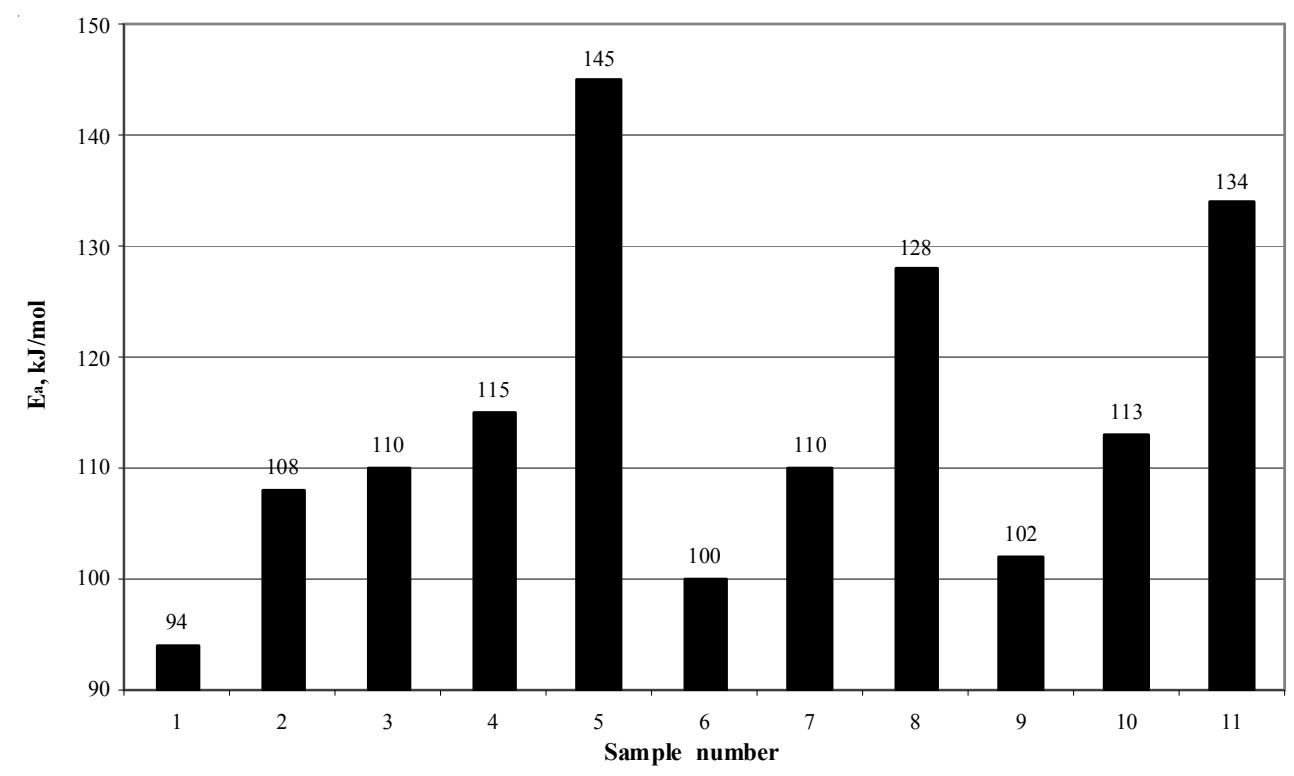

Fig. 4. The values of the activation energy of thermal oxidative degradation:

$1-\mathrm{PP} ; 2-\mathrm{PP}+\mathrm{I} 1010(0.5 \%) ; 3-\mathrm{PP}+\mathrm{mr} ; 4-\mathrm{PP}+\mathrm{mr}+\mathrm{I} 1010(0.5 \%) ; 5-\mathrm{PP}+\mathrm{mr}+\mathrm{I} 1010$ (a);

$6-\mathrm{PP}+\mathrm{s}(0.7 \%) ; 7-\mathrm{PP}+\mathrm{mr}+\mathrm{s}(0.5 \%) ; 8-\mathrm{PP}+\mathrm{mr}+\mathrm{s}(\mathrm{a}) ; 9-\mathrm{PP}+\mathrm{Ib} 561(0.4 \%) ;$

$10-\mathrm{PP}+\mathrm{mr}+\mathrm{Ib} 561(0.7 \%) ; 11-\mathrm{PP}+\mathrm{mr}+\mathrm{Ib} 561(\mathrm{a})$

opposite one can be observed when stabilizers and fillers are jointly introduced.

The use of pre-treated fillers leads to a significant increase of the activation of the energy of thermal oxidative destruction (samples 5,8 , 11). The greatest stabilizing effect while applying a new method of introduction is observed for Irganox 1010 (sample 5). At the same time there is a thermal stability increase of $26 \%$. It is explained by the high adsorption ability of a given stabilizer due to the presence of polar hydroxyl, carbonyl groups, benzene rings in its structure and a large specific surface of marble, to the presence on its surface of active sites capable to react with the polar groups of the stabilizer. The use of marble, treated with a solution of Irganox 1010, can reduce the required amount of a stabilizer up to 0.4 wt. \% (1.25 times less than at a traditional stabilizer introduction) with a significant simultaneous increase of thermal stability. In the case of the individual introduction of components - a filler and a stabilizer, the necessary concentration of the stabilizer is $0.5 \mathrm{wt}$. $\%$.

Thus, one can trace a tendency to the increase of resistance to the durable effect of temperature in the presence of atmospheric oxygen for compositions, obtained using a new method of introduction of PCM components. This may be concerned with the fact that the stabilizers existing on the surface of fillers are more uniformly distributed in the bulk of polymer matrix as the introduced amount of fillers is two orders higher than the amounts of stabilizers, dosed by a conventional manner. As a result, the fields in the polymer matrix with an overdose of the stabilizer, when it begins to function as the initiator of oxidative destruction are eliminated. It is possible to use the less amount of stabilizer as compared to the traditional PCM receiving technology due to its more uniform distribution and direct action in the matrix.

At elevated temperature the stabilizer starts to desorb from the surface of the filler, it neutralizes the action of macroradicals. A gradual stabilizer expenditure takes place, as a result the gradient of stabilizer concentrations appears in the bulk of the polymer and on the filler surface. The stabilizer desorbs from the filler and diffuses in a polymer matrix with a reduced stabilizer content to align the chemical potentials. Since the stabilizer desorbs dosed, the possibility to overdose the stabilizer is eliminated. This fact explains its prolonged and direct action. In addition during the saturation of fillers with stabilizers air is evacuated out of microcracks and pores, and oxygen is evacuated too. In conventional technology it comes together with the filler into a polymer matrix, additionally initiating oxidative processes leading to the destruction of macromolecules. 


\section{Conclusion}

A new method of stabilization of filled polymers by pre-saturation of the surface of fillers with stabilizers is developed. It will provide a significant resistance increase to thermal aging of compositions and a simultaneous significant stabilizer economy due to a more uniform distribution in the matrix, its direct desorption from the surface of the filler and a prolonged action compared with conventional technology of polymer composites production. The totality of data obtained in this work about the individual and joint action of fillers and stabilizers in the compositions of polypropylene can be used in the development of polymer composite materials based on other thermoplastic matrixes.

\section{REFERENCES}

1. Babayan V.G., et al. The Accelerated Test Methods of Chemical Additives in Polymer Materials [Methods for the preliminary assessment of antioxidants for plastics and elastomers]. Moscow, NIITEKHIM Publ., 1975. $31 \mathrm{p}$.

2. Bulychev N.A. Study of Polymer Adsorption on the Surface of Inorganic Pigments by Infrared Spectroscopy. Materialovedenie, 2009, no. 10, pp. 2-9.

3. Chatterjee A., Deopura B.L. Thermal Stability of Polypropylene/Carbon Nanofiber Composite. J. Appl. Polym. Sci., 2006, vol. 100, no. 5, pp. 3574-3578.
4. Dzgaylis Ch. et al. Adsorption From Solutions on Solid Surfaces. Moscow, Mir Publ., 1986. 488 p.

5. Greg C., Singh K. Adsorption. Specific Surface. Porosity. Moscow, Mir Publ., 1984. 306 p.

6. Huang R., et al. High-Density Polyethylene Composites Reinforced With Hybrid Inorganic Fillers: Morphology, Mechanical and Thermal Expansion Performance. Materials, 2013, vol. 6, no. 9, pp. 4122-4413.

7. Ivanova N.I. Adsorption of the Surfactant Mixture From the Aqueous Solutions on the Surface of Calcium Carbonate. Colloid Journal, 2000, vol. 62, no. 1, pp. 65-69.

8. Kalinchev E.L., et al. Progressive Stabilization Technology of Polymer Products. Polym. mater., 2008, no. 7, pp. 3-14.

9. Kandare E., et al. Probing Synergism, Antagonism, and Additive Effects in Poly(Vinyl Ester) (PVE) Composites With Fire Retardants. Polym. Degrad. and Stab., 2006, vol. 91, no. 6, pp. 1209-1218.

10. Lenartovich L.A., et al. Mutual Influence of Fillers and Stabilizers in the Polymer Composite Materials. Trudy BSTU, 2011, no. 4, pp. 98-102.

11. Malik J., Sidgi M. New Systems of Stabilizers in Polyolefin Water Pipes. Plastmassy, 2006, no. 10, pp. 36-39.

12. Mashko T.L., Kalugin E.V. Impact of New Copper-Containing Supplements on the ThermalOxidative Stability of Polycaproamide. Plastmassy, 2006, no. 1, pp. 37-41.

13. Pena J., et al. Interactions Between Carbon Black and Stabilizers in LDPE Thermal Oxidation. Polym. Degrad. and Stab., 2001, vol. 72, no. 1, pp. 163-174.

14. Wilen C.E., Pfaendner R. Improving Weathering Resistance of Flame-Retarded Polymers. J. of Appl. Polym. Sci., 2013, vol. 129, no. 6, pp. 925-944.

\section{СПОСОБ ПОВЫШЕНИЯ ТЕРМОУСТОЙЧИВОСТИ ПОЛИМЕРОВ С НАПОЛНИТЕЛЯМИ}

\section{Николай Романович Прокопчук}

Доктор химических наук, профессор, член-корреспондент Национальной академии наук Республики Беларусь, заведующий кафедрой технологии нефтехимического синтеза и переработки полимерных материалов, Белорусский государственный технологический университет prok_nr@mail.ru ул. Свердлова, 13А, 220006 г. Минск, Республика Беларусь

\section{Лилия Алексеевна Ленартович}

Кандидат технических наук, младший научный сотрудник, кафедра технологии нефтехимического синтеза и переработки полимерных материалов, Белорусский государственный технологический университет liliya.popova@mail.ru ул. Свердлова, 13А, 220006 г. Минск, Республика Беларусь 
Аннотация. В настоящей работе оценивается вклад стабилизаторов и наполнителей в повышение термостабильности полимерной матрицы композиционных материалов. Было показано увеличение термической стабильности композитов полипропилена в процессе предварительного насыщения поверхности наполнителем. Предложен метод насыщения поверхности полимеров стабилизирующим наполнителем.

Ключевые слова: стабилизатор, наполнитель, полимерный композиционный материал, адсорбция, полипропиленовые композиты. 